\title{
Acciones colectivas frente a la violencia. Disquisiciones a partir de un estudio de casos: Comuna 13 de Medellín (Colombia)
}

\author{
= \\ Mary Luz Alzate Zuluaga \\ Universidad Complutense de Madrid
}

\begin{abstract}
Resumen: En este artículo se analizan las modalidades y estrategias de acción que los sujetos colectivos producen para enfrentar la violencia, a partir de un estudio de casos de acciones colectivas producidas en el contexto del conflicto interno armado colombiano, caracterizándolas como modalidades de acción política intentando revertir, transformar o alterar las relaciones de poder que a través de tal violencia se pretende implantar. Concluyendo en la emergencia de un nuevo escenario de lo público, que plantea la existencia de orientaciones y formas de acción opositoras a la dominación armada, e ilustradoras de una pluralidad de alternativas culturales, políticas y sociales civilistas y democráticas.
\end{abstract}

Palabras-clave: acción colectiva; política; violencia; Medellín; Colombia

Abstract: This article discusses the modalities and strategies that produce collective subjects to deal with violence, from a case study of collective action produced in the context of the Colombian internal armed conflict, characterizing them as forms of political action trying to reverse, transform or alter the power relations through such violence is intended to implement. Ending in the emergence of a new stage of the public, positing the existence of guidelines and forms of action armed opposition to domination and illustrations of a plurality of alternative cultural, political and social civility and democratic.

Keywords: collective action; politics; violence; Medellín; Colombia

OPINIÃO PÚBLICA, Campinas, vol. 18, n², novembro, 2012, p. 427 - 451 
OPINIÃO PÚBLICA, Campinas, vol. 18, no 2, novembro, 2012, p. 427 - 451

\section{Introducción $^{1}$}

El contexto social y político colombiano ha estado cruzado y alimentado, durante más de medio siglo, por problemas de inestabilidad e ilegitimidad política, impunidad, desigualdad económica y social, conflicto armado entre grupos insurgentes, grupos paraestatales y las Fuerzas Armadas oficiales, a la par con la pervivencia en el ejercicio público de cacicazgos y clientelas.

El surgimiento de las guerrillas en la década de los años sesentas estuvo marcado, primero, por la existencia de las restricciones que tuvieron otros partidos y fuerzas políticas para acceder a los mecanismos democráticos de ejercicio del poder, segundo, en el ámbito internacional, por la influencia comunista de la Revolución Cultural China iniciada en 1949 y la Revolución Cubana de 1959. principalmente en Latinoamérica- Iiderada por el Che Guevara y Fidel Castro. Los grupos subversivos que continúan activos (Fuerzas Armadas Revolucionarias de Colombia -Ejército del Pueblo y Ejército de Liberación Nacional) tendrán su relato fundacional a partir de hechos de orden público local y de estos acontecimientos políticos internacionales.

El surgimiento y enfrentamiento de terceros actores, como los grupos paramilitares, creados bajo diferentes denominaciones según la coyuntura, ya sea "escuadrones de la muerte", "grupos de limpieza" o "grupos de autodefensas", y el narcotráfico con su poder corrosivo de corrupción administrativa y jurídica, han sido incorporados a la realidad nacional como otras de las grietas que se abren en la sociedad, configurando todo un mapa circunstancial de la violencia a partir de la década de los años setentas.

Algunos investigadores (Leal Buitrago, 1997; PeCAut, 1997; Guerrero, 1998; Fajardo, 1999; ZAFFORD y PALACIOS, 2002) han planteado que la confrontación armada que se establece entre Estado y guerrillas, a partir de la década de los años sesenta, se debió a la acumulación de conflictos estructurales. Entre estos conflictos se encuentran: el territorial -al no haberse dirigido una distribución equitativa de las tierras-, el administrativo -ya que no se asumió la modernización y reforma de las instituciones políticas, entre ellas, los partidos políticos tradicionales-, y el desarrollista -al incorporar formulas económicas externas a las necesidades internas que urgían para el país- (LEAL BUITRAGO, 1997, p. 53-57).

Ante los conflictos sociales se han emprendido medidas formales y reformas legales con el objeto de otorgarle mayor participación y poder decisorio a las comunidades, como es el caso del proceso de descentralización de las competencias administrativas y de los recursos públicos comenzado desde 1986 o la Constitución Política de 1991. Sin embargo, estos han sido avances de carácter normativo, más formales que reales, y con la intensificación de la confrontación armada durante la década de los años noventa lo que experimentaron esos conflictos es su exacerbación.

\footnotetext{
1 Esta es una síntesis de los resultados y principales aportes de la tesis doctoral defendida por la autora en la Facultad de Ciencias Políticas y Sociología de la Universidad Complutense de Madrid. El análisis e investigación de campo con las entrevistas citadas fue desarrollado en el marco del proyecto "Resistencia Civil No Armada al Conflicto Armado, la Exclusión Social y la Pobreza. Casos Comunas 8, 9 y 13 de Medellín. 2002-2006”, dirigido por Jaime Rafael Nieto López (investigador principal), Mary Luz Alzate y Katherine Higuita (co-investigadoras), con el apoyo del Comité para el Desarrollo de la Investigación (CODI), Universidad de Antioquia. 2007-2008. Una primera versión en inglés de éste artículo está publicada en el volumen 22, número 44, de la revista Frontera Norte correspondiente al segundo semestre (julio-diciembre) de 2010.
} 
ZULUAGA, M. L. A. Acciones colectivas frente a la violencia. Disquisiciones a partir...

De este modo, en primera instancia se encuentra el conflicto territorial, que plantea la situación de pobreza y desempleo vivido agudamente en el área rural por los campesinos colombianos, y relacionado con este, la tendencia de la distribución de la propiedad hacia la concentración en pocas manos $^{2}$. Esta es una problemática que pone en evidencia la existencia de una irracional distribución de los usos del suelo, debido a la ocupación para la ganadería extensiva de grandes extensiones de tierra aptas para la agricultura, lo que ha causado su subutilización a la vez que se da una sobreutilización de suelos poco propicios para el cultivo de minifundio (PNUD, 2003).

Esta situación en el área rural se ha visto agravada durante los últimos diez años y ha repercutido en el desempleo de las ciudades colombianas, debido a que las zonas de predominancia latifundista se han caracterizado, dentro de la dinámica del conflicto armado, por ser zonas expulsoras de población en forma violenta bajo la actuación de grupos que brindan seguridad privada a los grandes propietarios. Al respecto, fue definido un proyecto paramilitar consolidado gracias a la alianza entre grupos de autodefensas, autoridades locales, fuerza pública, empresarios y ganaderos (ESCOBEDO, 1998). Estas organizaciones autodenominadas de autodefensas Campesinas se fueron constituyendo, durante más de diez años (entre 1994 y 2005), en organizaciones que exclusivamente garantizaron el control de las zonas donde han estado asentadas.

En segundo lugar, la existencia de un conflicto político-administrativo ha caracterizado durante décadas al Estado colombiano por la poca legitimidad y transparencia de sus instituciones, en esta situación influye la corrupción administrativa con la frecuente apropiación de los fondos públicos para el interés privado de sus funcionarios, en detrimento de la inversión social. Hacen parte también de esta situación las viejas prácticas clientelistas que continúan los partidos políticos existentes, esto es, los candidatos ofrecen a sus electores favores económicos o prebendas y ventajas políticas antes que programas de gobierno con un proyecto de sociedad consecuente con las ideas políticas de los partidos. En años recientes se comenzó a hablar de la existencia de un clientelismo armado por parte de los actores del conflicto. Así lo describe el Informe Nacional de Desarrollo Humano del año 2003 :

\footnotetext{
"en distintos municipios, provincias o departamentos, la mezcla entre latifundismo autoritario, clientelismo electoral, narcotráfico y conflicto armado hizo que el poder económico y político cayera en manos de una especie de 'mafia' -una mezcla de señores de la guerra, criminales de cuello blanco y delincuentes que posan de señores" (PNUD, 2003, p. 387).
}

Así mismo, a este conflicto político-administrativo contribuye la precaria presencia de las instituciones públicas en las regiones, ya que muchas veces se hace presencia, exclusivamente, a través del ejército, y en muchos otros casos, es la seguridad ciudadana el mayor problema a resolver por las administraciones locales. En otras circunstancias, la presencia de las instituciones públicas se caracteriza por una mínima autonomía frente a las élites locales, con lo cual se está planteando una débil

\footnotetext{
2 “La mayoría de las tierras agrícolas colombianas se encuentran ocupadas por pastos. De una extensión de 114 millones de hectáreas, en el país se explotan menos de 40 millones. De éstas el $91 \%$ corresponde a una ganadería que se desarrolla casi en su totalidad en forma extensiva." (Según los datos registrados en Pequeño Larousse Ilustrado, edición de Ramón García-Pelayo y Gross, 1995, p. XXIV) 
OPINIÃO PÚBLICA, Campinas, vol. 18, no 2, novembro, 2012, p. 427 - 451

gestión que va en detrimento de la gobernabilidad y una incapacidad estatal para hacer respetar, en condiciones de igualdad, los derechos de la ciudadanía.

En tercer lugar, la existencia de un conflicto en la distribución económica, por el alto grado de exclusión social, para un país que basa su economía en un sin número de actividades de enclave, lo que ha implicado la explotación a gran escala de los recursos naturales sin que las ganancias y excedentes obtenidos por las empresas nacionales y multinacionales haya redundado en beneficio de los habitantes de las regiones de donde proceden los principales recursos. El país comenzó una carrera de internacionalización de la economía con apertura a los mercados externos a partir de 1990, sin embargo, el discurso de la globalización que llegó a los ciudadanos no ha garantizado la igualdad para acceder a sus bienes, y en la actualidad ante un inminente Tratado de Libre Comercio entre Colombia y Estados Unidos no hay claridad frente a las responsabilidades institucionales de la actual situación de fragmentación social y pobreza.

El objetivo de éste artículo es presentar el análisis de las acciones colectivas producidas durante los años 2002 al 2006 para enfrentar las distintas situaciones de violencia derivadas del conflicto interno armado de Colombia. Acciones colectivas localizadas en un territorio urbano en el que confluyen distintos bandos armados de carácter estatal, paraestatal e insurgente, además de los narcotraficantes y la delincuencia común.

Este es el caso de la Comuna 13 de Medellín, un asentamiento conformado por barrios deprimidos social y económicamente, y en el que se ha dado, como en ninguna otra comunidad urbana, la confluencia de micro-poderes autoritarios ilegales del orden local y nacional, con la presencia de grupos de milicia urbana, bandas criminales, denominadas BACRIM, que controlan el micro-tráfico de armas y drogas en estos barrios populares y la pervivencia de células urbanas de las guerrillas de las FARC-EP y el ELN. Cada uno de estos actores se disputa el control sobre el territorio de la comuna 13, lo que ha significado a la vida cotidiana barrial de sus moradores, la existencia de diferentes códigos de conducta y movilidad en un mismo barrio, y ante cualquier falta a la norma impuesta por el grupo armado dominante de una zona en particular; como puede ser para los jóvenes hombres la prohibición de llevar el cabello largo, con tatuajes en el cuerpo, o el no transitar de un sector a otro a determinadas horas del día, genera el asesinato, desaparición forzada o, en el mejor de los casos, la amenaza y el desplazamiento forzado del infractor y su familia.

Lo que disputan estos grupos ilegales, además del control arbitrario del poder, es el acceso económico a las ganancias provenientes del cobro extorsivo a tenderos, comerciantes, transportadores, entre otros, a manera de impuestos que se arroga un micro-poder armado dominante y también significa el control del mercado barrial de la venta de drogas ilegales.

A su vez, la Comuna 13 fue un escenario que llegó a representar el laboratorio urbano para el despliegue de la "Política de Seguridad Democrática" defendida por el anterior presidente Álvaro Uribe Vélez, lo que significó una expansión de fuerza pública a lo largo de las laderas de esta comuna en el año 2002, con los operativos militares conocidos públicamente como Operación Orión y Operación Mariscal, bajo el argumento de frenar y controlar los enfrentamientos armados protagonizados por grupos de milicias urbanas, grupos paramilitares y delincuencia común. 
ZULUAGA, M. L. A. Acciones colectivas frente a la violencia. Disquisiciones a partir...

En la política interna de Colombia dicha decisión de intervención militar se dio tras un periodo de desgaste y fracaso de procesos de negociación para la paz entre el gobierno nacional y la guerrilla de las FARC (1998-2001), proceso que se interrumpió antes de concluir el periodo presidencial de Andrés Pastrana Arango. Con la elección del presidente Álvaro Uribe Vélez, en el año 2002, triunfó la propuesta de "recuperar la autoridad democrática" a través del fortalecimiento de la seguridad pública, pero que más pareció una política de "seguridad preventiva", acorde con la estrategia de intervención y militarización de los conflictos políticos a nivel mundial, profundizada luego de los atentados del 11 de Septiembre del año 2001 en Estados Unidos, por la Presidencia de George Bush ${ }^{3}$.

Este contexto lo habitan, paradójicamente, cientos de pobladores dinámicos, creativos y absolutamente entusiastas por la vida y contrarios a cualquier proyecto autoritario y excluyente de la sociedad. De acuerdo a lo cual el análisis se centra en dos escenarios, el primero es el de la identificación de los sujetos sociales como los protagonistas y constructores de los proyectos civilistas y democráticos de la sociedad, buscando mostrar que éstos agentes sociales son los dueños de sus propios destinos y proyectos de vida, más que constituirse exclusivamente en las victimas de la violencia que han experimentado. Y el segundo escenario, es la identificación de la violencia como un contexto configurador de la acción colectiva, surtiendo un doble efecto, al desarticular y amenazar a los activistas y movimientos contestatarios, pero también, al dinamizar y motivar nuevas formas y repertorios de acción que logran contrarrestar las situaciones de violencia y exclusión social y política que se busca enfrentar con la movilización social identificada en este estudio.

A continuación se presenta, en el primer apartado, una breve descripción de la metodología utilizada, seguida de una síntesis de la discusión sobre los temas de violencia, política y acción colectiva. En segundo lugar, los principales hallazgos y resultados de la investigación y una propuesta de aporte al tema de la acción colectiva y la política y, por último, las conclusiones del estudio de casos de la Comuna 13 de Medellín (Colombia).

\section{Metodología para el estudio de casos sobre las acciones colectivas frente a la violencia}

La ruta teórica que orientó el desarrollo del análisis sobre los dos escenarios mencionados -los actores sociales y la violencia con sus efectos- fueron, en primer lugar, un examen de los temas de la violencia, la política y la acción colectiva, a la luz de las transformaciones derivadas de la globalización capitalista y sus consecuencias en el ámbito local. Y en segundo lugar, una estrategia práctica, que se desarrolló con el estudio etnográfico de los casos de acciones colectivas identificadas en el ámbito local de la conformación barrial conocida administrativamente como Comuna 13 de la ciudad de Medellín, utilizando para ello técnicas de investigación, tales como las entrevistas a los activistas y personas directamente implicadas en la producción de la acción colectiva frente a las situaciones de violencia, complementada con los recorridos de observación de la vida barrial y la realización de talleres

\footnotetext{
3 “La retórica que nos dice que el mundo ha cambiado después del 11 de septiembre de 2001 ha privilegiado la experiencia de los estadounidenses como algo único, asumiendo que las formas de terrorismo con las cuales otros países han tenido que vivir durante algo más de treinta años, como es el caso de Sri Lanka, eran relevantes para esas sociedades, pero no para la humanidad en general. El ataque a los Estados Unidos se describe nada menos que como un ataque a la civilización misma." (DAS, 2008, p. 497)
} 
OPINIÃO PÚBLICA, Campinas, vol. 18, no 2, novembro, 2012, p. 427 - 451

comunitarios focalizados en las temáticas de la violencia, el conflicto armado, la acción colectiva de resistencia civil y la exclusión social y económica.

\section{El Examen teórico de los temas violencia, política y acción colectiva}

\section{La violencia: Entre la ambigüedad y la despolitización}

La violencia ha sido un tema discutido y definido a partir de elementos dicotómicos; estos son, entre su carácter público o su carácter privado, entre la responsabilidad individual (IGNATIEFF, 2005) o colectiva (TILLY, 2004), entre lo antiguo o lo nuevo de acuerdo a la intensidad, velocidad, espacialización y motivación de los conflictos de hoy frente a los de antaño (KALDOR, 2005; MÜNKLER, 2004 y 2005; MARCHAL y MESSIANT, 2004; WaLDMANn, 1999). Elegir un elemento en detrimento del otro en cada una de estas disyuntivas conduce a una mirada restrictiva y sesgada que no permite dimensionar la ambigüedad de las realidades que involucra la violencia (KALYVAS, 2004), y, mucho menos, reconocer las posibles articulaciones propias de un mundo cada vez más ínter-penetrado por circunstancias del orden local con el global y viceversa (Fazio Vengoa, 2007; CAstells, 1995; SAsSen, 2007; Mattelart, 2002).

La utilización de la violencia como medio o recurso de acción ha servido a los más ensalzados ideales de sociedad, así como a los más obtusos y depredadores intereses. Así mismo, escapando a cualquier inmediatez en la precisión temporal y espacial de la violencia, las de hoy, son violencias que informan de dinámicas recientes, pero que pueden estar reconfigurando y redimensionando conflictos estructurales no resueltos de las distintas sociedades involucradas. De este modo, se busca reconocerla desde su ambigüedad, dualidad y amalgama en los procesos de desintegración y reintegración social y política. Esto es, su reconocimiento como un elemento inherente a las experiencias de las relaciones humanas (SUBIRATS, 2002), en cualquier localización y estadio de la civilización en el que nos encontremos.

Teniendo en cuenta las transformaciones espaciales experimentadas en las últimas décadas, la violencia producida en una localidad en particular no se puede entender hoy exclusivamente desde las condiciones sociales, políticas, culturales y legales del contexto de los Estados nacionales. La idea de aparatos estatales ejerciendo el monopolio de la violencia está cada vez más puesta en entredicho debido al sinnúmero de transacciones materiales -incluyendo las transacciones ilegales como el tráfico ilegal de armas-, ideológicas, sociales y políticas que emergen y cada día son más difíciles de controlar al interior de los territorios nacionales, sobre todo porque se trata de actividades que no están localizadas (GIDDENS, 1993; BAUMAN, 2005) debido a que hacen parte de las transacciones que han entrado al lugar fluido de las redes internacionales, y cuyas decisiones tampoco dependen de un único actor. En este sentido los Estados hoy, "es muy poco lo que pueden monopolizar de manera realista, excepto la idea del territorio como punto diacrítico de la soberanía" (APPADURAI, 1999).

Ahora bien, la actual indefinición e inclasificación de la violencia entre los límites de lo público y lo privado (MÜNKLER, 2005), entre el espacio doméstico nacional y el mundial, entre su carácter estatal y aestatal (GLEDHILL, 2000), que también propicia la misma perspectiva de indeterminación y ambigüedad frente a la distinción de la violencia por su carácter individual o colectiva, conduce también a un planteamiento despolitizado de la violencia, con graves riesgos por el argumento de nula responsabilidad de quien la produce y las consecuencias que genera. Es decir, la violencia entendida desde su 
ZULUAGA, M. L. A. Acciones colectivas frente a la violencia. Disquisiciones a partir...

ambigüedad e inclasificación, también es des-responsabilizada, hundiendo el asunto en un espacio vacío, en una "tierra de nadie" (AGAMBEN, 2005, p. 24). De este modo, poner en entre dicho el monopolio efectivo en el ejercicio de la violencia por parte del Estado en la era global, no quiere decir la aceptación de la afirmación de la privatización y comercialización de la guerra (MüNKLER, 2004, p. 6) y, como efecto, la desestatalización de la violencia o la desaparición de la responsabilidad estatal en los conflictos.

Lo que se afirma, es el reconocimiento de la multiplicidad de grupos armados locales, grupos de delincuencia organizada y redes internacionales del terrorismo, así también de gobiernos autoritarios y militaristas haciendo uso de la violencia en esa reestructuración de las relaciones de poder en el ámbito local, regional y global; lo que incluye la concentración de recursos naturales y territorios bajo el control de grupos de élites de poder. De acuerdo con Lemke, "El análisis de Foucault sobre la gubernamentalidad neoliberal muestra que el 'llamado repliegue del Estado' es en realidad una prolongación del gobierno; el neoliberalismo no es el fin de la política sino una transformación de ella que reestructura las relaciones de poder en la sociedad" (LEMKE, 2006, p. 16). De este modo,

\footnotetext{
“El mercado promete, pues, una extensa reproducción de los recursos violentos del estado, y las injerencias foráneas clandestinas de gobiernos supuestamente 'responsables y democráticos' han desempeñado un importante papel a la hora de fomentar la violencia como medio para conseguir objetivos políticos en todo el mundo. Si el mundo que han creado los imperios hoy les causa alarma debido a unos desórdenes que ya no pueden controlar, tales desórdenes son, al fin y al cabo, creación suya" (GLEDHILL, 2000, p. 254).
}

En ese afán de despolitizar y quitar responsabilidad al Estado, el pensamiento de Foucault (2000) se muestra mucho más visionario al afirmar: "si el discurso de las razas, de las razas en lucha, fue sin duda el arma utilizada contra el discurso histórico político de la soberanía romana, el discurso de la raza (la raza en singular) fue una manera de dar vuelta a esa arma, de utilizar su filo en beneficio de la conservación de la soberanía del Estado" (FoucAuLT, 2000, p. 81). De este modo, el sentido que adquiere la producción de determinada violencia se debe entender dependiendo de su despliegue en especificas relaciones de poder. Así, la utilización de las tecnologías de la información en el ámbito geopolítico de la guerra y de la paz se realiza en pos del acaparamiento monopolista de los mercados en un mundo unipolar, lo que conduce al argumento de una estrategia de seguridad global, caracterizada por la intervención militar circunscrita a la ampliación "quirúrgica" o "limpia" del modelo global de la democracia del libre mercado.

Las transformaciones históricas y culturales de la violencia van produciendo diferentes contornos de la política, dentro de los cuales los sujetos colectivos inician nuevas estrategias de acción y movilización social. A su vez, en las desiguales relaciones de poder se ha utilizado la violencia como estrategia de acción. Es decir, tanto la violencia como la política y -dentro de ésta la acción colectiva-, más allá de realidades estructurales fijas, diferenciales y esenciales, hacen parte de los procesos de construcción de la vida en común. De la forma como se construyan las relaciones sociales en el marco de procesos de violencia y política, dependen las consecuencias para las distintas posibilidades de la 
OPINIÃO PÚBLICA, Campinas, vol. 18, no 2, novembro, 2012, p. 427 - 451

experiencia en común. Se discutirá, a continuación, el tema de la política y la acción colectiva con la reflexión que sobre lo público han suscitado las transformaciones del Estado y el posicionamiento del mercado en la era de la globalización, ampliando las posibilidades de la acción política por fuera del marco estatal y de la hegemonía global del mercado.

\section{La política desde órdenes plurales de existencia}

Esta es una perspectiva de la política que busca superar su definición y estructuración exclusivamente desde unas relaciones centrales, fijas y localizadas en las actividades administrativas del Estado (FouCAult, 2000), escenario por excelencia en el que había sido decidida y gestionada la representación de la soberanía del pueblo. Un nuevo escenario de la política es el que se prefigura en el reconocimiento de la capacidad del ciudadano de auto-representarse y constituir las condiciones para un bienestar común, basado en el criterio de unas relaciones de poder cambiantes y que oscilan permanentemente entre la disolución, la fragmentación y la inclusión a una comunidad de ciudadanos. Es la afirmación de una política de las diferencias, que establece débiles límites en las relaciones sociales, límites que recrean luchas materiales y de significados que derivan permanentemente en nuevas configuraciones de poder.

Esta política definida en los límites es un reconocimiento de las singularidades, entendidas no desde una unidad esencial, sino como expresión de la pluralidad, pero también de la ambivalencia, esto es, la multiplicidad de diferencias interrelacionadas, afirmadas como distintas fuerzas en interacción habitando un espacio diverso (VIRNO, 2003; 2004). ¿Qué hacer en esos escenarios vinculantes entre las personas por fuera de la soberanía estatal? ¿Qué argumento continuar en la apertura de nuevos horizontes de posibilidad por fuera del actual modelo de mercado-Estado? ¿Cómo se construye la política en los nuevos escenarios globales y locales?

La economía de mercado trasnacional en sus diferentes facetas -compra y venta de servicios, especulación en los precios del suelo. es un actor territorial que no tiene rostro, ya que tiene la capacidad de mimetizarse con otras prácticas públicas, pero esa invisibilidad protagónica es contraria a su fuerza y capacidad transformadora de la realidad, del entorno espacial y social.

Siguiendo el anterior planteamiento, la ejecución y proyección de obras de desarrollo infraestructural en la Comuna 13 o cercanas a este entorno, tiene varias consideraciones de acuerdo a lo que ha significado en la vida social de estos barrios, en primer lugar, consolida la imposición de un modelo de desarrollo de la ciudad basado en la trasnacionalización del mercado y para el cual la oferta de servicios sociales, domiciliarios, financieros, de movilidad vial, de seguridad, entre otros, son ofertados a la población, siempre y cuando pueda pagarlos, con lo cual son más las restricciones y exclusiones que los "servicios prestados" a los habitantes; un discurso que entra en contradicción con aquél que afirma la garantía de los derechos fundamentales de la ciudadanía. En segundo lugar, la cadena de exclusiones socioeconómicas y sociopolíticas se reproduce y multiplica en el territorio de las comunas populares, debido entre otras, a la eliminación física por medios violentos de toda voz que disienta de ese proceso institucionalizado de configuración territorial y al poco alcance de proyectos cuyo objetivo sea la solución de problemáticas básicas de la comunidad -empleo, salud, educación, vivienda, servicios públicos domiciliarios. 
ZULUAGA, M. L. A. Acciones colectivas frente a la violencia. Disquisiciones a partir...

Una transformación en la interpretación de la violencia a partir de los efectos de la globalización, pasa por la mirada de la construcción de estereotipos de los "terroristas" y violentos en los medios de comunicación y cadenas de noticias internacionales y el modo cómo estos estereotipos son consumidos y retroalimentados en las realidades locales. Así, la relación del lugar de procedencia de los sujetos y la edad (jóvenes, por ejemplo) con proclividad hacia la violencia, lo que genera es la formación de estereotipos de cultura violenta de un grupo poblacional en particular, que en el tratamiento de la opinión pública tiene una facilidad a desplazarse hacia la estigmatización y discriminación social de la población involucrada. El rumor y la distorsión de las relaciones cotidianas, así como el consumo de imágenes e información que entran a respaldar el rumor inicial, es uno de los medios, entre otras vías, de adquisición de la resonancia pública y legitimación para la criminalización de las conductas, o para la "criminalización de la pobreza" como lo expresa Bauman (1999, p.161), por parte de los aparatos de seguridad estatal. Es el papel fundamental que tiene el terrorismo de Estado en la producción y reproducción de la violencia como su propia condición de existencia.

De ahí que, los jóvenes y los pobres criminalizados en su conducta, permanentemente tengan que soportar la vigilancia, el cacheo policial, la persecución en todas las actividades sociales y políticas que realizan, al punto de disminuir las oportunidades laborales, entre otros factores, por su procedencia de los barrios periféricos de las ciudades, produciendo de este modo una nueva violencia, en este caso simbólica, que estructura, condiciona y genera nuevos contextos de violencia física a través de la intervención estatal.

La paulatina desregulación estatal de los asuntos comunes a los ciudadanos y el fortalecimiento del modelo económico del libre mercado, de acuerdo a los procesos globales de transformación técnica, social, política, económica y cultural, obliga la emergencia de definiciones sobre la política desde las construcciones y discursos que sobre el asunto tengan los propios sujetos sociales en acción. Las respuestas a algunas de las inquietudes formuladas son afrontadas desde las singulares experiencias de acción colectiva, en estas se ensayan distintas iniciativas a las amenazas generadas tanto por las situaciones de violencia como por la flexibilización laboral y las desregulaciones de las relaciones público/privadas de la vida en la sociedad contemporánea. Son experiencias contra-hegemónicas que ensayan nuevas formas de ser y estar en el mundo.

\section{Las acciones colectivas como experiencias políticas alternativas}

Las acciones colectivas, desde la perspectiva defendida aquí, se definen como un ejercicio político y social con mayores o menores niveles de organización- que busca el logro de demandas comunes. Sin embargo, su sentido es más profundo que la simple visión instrumental de la acción, por ello las acciones colectivas, de acuerdo con Melucci (1996), construyen sistemas emergentes de cultura política que se entretejen con la vida diaria, proveen nuevas expresiones de identidad y van en oposición directa al orden dominante.

Teniendo en cuenta los aspectos más abarcadores y heterogéneos de estas experiencias, las acciones colectivas son expresiones visibles de una orientación política, ya sea en defensa del establecimiento político y económico imperante, o en protesta, resistencia, oposición, a ese orden social establecido. Estas manifestaciones colectivas pueden ser interpretadas desde el reconocimiento del 
OPINIÃO PÚBLICA, Campinas, vol. 18, no 2, novembro, 2012, p. 427 - 451

carácter multidimensional de la acción colectiva y la complementariedad de aspectos de análisis para su conocimiento, tales como, el origen de las acciones colectivas y las movilizaciones sociales, la lógica de acción que las ha orientado, la forma organizativa adquirida y el impacto obtenido con la acción, la autodefinición de los actores sociales, el modo cómo han logrado actuar conjuntamente y mantenerse, ya sea frente a sus adversarios o en un proyecto de movilización social sostenido frente a la sociedad hegemónica.

El acercamiento a los y las líderes y activistas sociales ha sido desde su reconocimiento como protagonistas de sus propios horizontes de posibilidad, al elegir la no-violencia desde una actitud activa, la objeción de conciencia, la no colaboración con los grupos armados, la autonomía de las acciones comunitarias emprendidas, la denuncia frente a los excesos y violaciones de los derechos humanos por parte de los violentos, la constitución de proyectos culturales, sociales y políticos alternativos al proyecto de sociedad vigente, pese a los riesgos y el precio que ya otros y otras líderes y activistas han pagado con su propia vida. Pretendiendo con ello, cuestionar la atribución de la importancia excesiva que se otorga al poder represivo y las violencias de todo orden en la limitación, desarticulación y eliminación de los poderes y proyectos socio-políticos y culturales alternativos.

\section{Hallazgos y resultados}

Para los años 2002 al 2006 fueron identificados nueve actores sociales (Juegos Cooperativos para la No-Violencia -Jughandi-, Corpades, Caravana por la Vida, Realizadores de Sueños, Corporación Sal y Luz, Red Cultural Expresarte, Asociación de Mujeres Las Independencias -AMI-, La Elite Hip Hop, Son Batá) como los convocantes y protagonistas de diversas acciones colectivas frente a la violencia y el conflicto armado producidas en los barrios periféricos de la Comuna 13 -barrios localizados en la ladera occidental de la ciudad de Medellín-, como una forma de resistir, denunciar, enfrentar y generar nuevas alternativas sociales, diferente a la violencia de todos los actores armados que allí confluían.

Estas experiencias de acción fueron heterogéneas, con sus matices y contrastes entre ellas, que se fueron mostrando poco a poco, obligando a desprenderse ligeramente de un marco analítico preestablecido sobre la acción colectiva, al revelar una variedad de acciones y procesos organizativos tenuemente definidos y estructurados, pero que asombraron y deslumbraron en su sencillez, sutilidad, creatividad, y, sobre todo, firmeza frente a los actores armados y frente a la privación de oportunidades económicas y sociales vividas por la mayoría de sus protagonistas. Aún así, fueron acciones colectivas, interpretadas a partir de la constitución de componentes de la movilización social, tales como, el contexto político, la percepción de injusticia, la eficacia de la acción, la construcción de identidades colectivas y la conformación de una política cultural local.

De este modo, se encontró que las acciones colectivas producidas en la Comuna 13 están condicionadas, recreadas y dinamizadas por elementos como el contexto de exclusión socioeconómica y de conflictividad violenta que las enmarca. Pero además, existen otros aspectos del contexto político nacional y mundial que interfieren en la producción de cada una de las acciones colectivas identificadas, entre éstos, la Política de Seguridad Democrática del gobierno nacional periodos 2002-2006 2006-2010, la amenaza del terrorismo mundial después de los atentados del 11.S del 2001. Y en el ámbito local, el enfrentamiento entre actores armados en los barrios de la Comuna 13 , las amenazas a la vida y el riesgo 
ZULUAGA, M. L. A. Acciones colectivas frente a la violencia. Disquisiciones a partir...

permanente de líderes sociales y población civil, la salida de la mayoría de las organizaciones no gubernamentales que hacían presencia en la Comuna 13 en el año 2002, la desarticulación de acciones colectivas pre-existentes. En contraste, también hace parte de este contexto político, la emergencia de nuevos actores sociales movilizados directamente frente a la violencia, la persistencia de algunos actores sociales con tradición en la zona y el acompañamiento de movimientos sociales locales (Red Juvenil) y Nacionales (Ruta Pacífica de las Mujeres/Mujeres de Negro) a las diversas acciones colectivas producidas para enfrentar la violencia ${ }^{4}$.

Dentro de los aspectos relacionados con la percepción de injusticia, como elemento a partir del cual se analizó la configuración de la acción colectiva, los actores sociales mencionan la violencia directa por parte de los actores armados sobre lideres sociales y población civil en general, la realización de operativos militares por parte de la fuerza pública y los combates en medio de la población civil, la intimidación a líderes sociales, la amenaza y prohibición de actividades sociales, políticas y culturales. Otros aspectos que hacen parte de la percepción de injusticia por parte de los actores sociales fueron las restricciones sufridas por los pobladores para la libre circulación entre los barrios de la Comuna 13, el control militar permanente, la estigmatización de jóvenes por proceder de barrios pobres y con una presencia histórica insurgente, el imaginario bélico y los juegos alusivos a la guerra que les ha quedado a los niños y niñas en este contexto.

La eficacia de la acción colectiva ha sido interpretada a partir de la tradición de autogestión barrial, de la creatividad y la imaginación cultural leída en clave de resistencia civil, de la capacidad para hacer visible la situación de violencia y violaciones de los derechos humanos de la población. Además de las relaciones de confianza, solidaridad y trabajo articulado en redes de las organizaciones sociales locales, de la emergencia de nuevos actores sociales organizándose con mensajes de exigencias de libertad de expresión, autonomía barrial y retirada de actores armados del territorio.

El otro elemento configurador de la acción colectiva analizado ha sido la construcción de identidades, en el estudio de casos se identificaron, de género, juveniles, artísticas y musicales, lo que ha permitido la creación de un proceso de política cultural desarrollado a través de unas estrategias organizativas comunitarias para enfrentar civilmente a los actores armados de todas las procedencias (guerrilla, paramilitar, narcotráfico, delincuencial y estatal) y a las dinámicas de guerra en el territorio de la Comuna 13. A través de esta construcción identitaria se ha posicionado a los jóvenes y mujeres, en particular, como interlocutores directos de organizaciones sociales, ya no como víctimas o personas reclutadas para engrosar las filas de algún actor armado, sino como los artífices de sus propios destinos.

Los jóvenes con intencionalidad política disidente frente a los actores armados y a las violaciones a los derechos humanos, se han dado cuenta que tienen mucho que aportar a la construcción de comuna y de ciudad, lo que ha propiciado la articulación de actores sociales juveniles en torno a la planeación de un futuro por fuera del conflicto armado, a la vez que a la creación de liderazgos

\footnotetext{
4 En Colombia a pesar de la fragilidad de muchos de los procesos sociales organizativos y la poca efectividad frente a los actores armados, hoy se puede hablar de acumulados sociales y políticos frente los violentos. La década de los años ochentas fue particularmente activa para las organizaciones indígenas, los colectivos de campesinos afro-colombianos y las organizaciones de mujeres. Y, desde mediados de los años ochenta, un sector de la población se ha manifestado en defensa de la vida y los derechos humanos como respuesta a la violencia procedente de distintos grupos armados. En los años noventa se vivieron diversas movilizaciones sociales y acciones multitudinarias que han buscado el respeto de la vida, los derechos humanos y el derecho internacional humanitario de la población civil por parte de los grupos involucrados en el conflicto armado.
} 
OPINIÃO PÚBLICA, Campinas, vol. 18, n², novembro, 2012, p. 427 - 451

femeninos y de confirmación de la autonomía ciudadana, con la generación de mecanismos de reflexión frente a las vivencias y la cotidianidad con los actores armados.

En el caso de la Comuna 13, las acciones colectivas crean una política cultural local vinculada a la defensa de la vida, que enfrenta a los violentos y al conflicto armado y democratiza los lugares públicos (las calles, los parques, los callejones, las laderas), recuperándolos para el uso común y libre circulación de todos los pobladores. Se recurre a la adopción de la no-violencia desde una actitud activa, a la objeción de conciencia y la no colaboración con los armados, a la autonomía de las acciones comunitarias emprendidas y a la promoción de valores civilistas de convivencia y respeto de las diferencias. Se ha aprendido a reconocer que a través de las manifestaciones artísticas y culturales se pueden romper las barreras y los límites bélicos, proponiendo así un nuevo escenario de la política local que reconoce la capacidad del ciudadano de auto-representarse y constituir las condiciones para un bienestar común.

A continuación se presenta en la Tabla 1 una síntesis de las modalidades de acción identificadas, con sus impactos o consecuencias y el actor político que las protagonizó.

Tabla 1

Síntesis de los repertorios de acción identificados, estrategias, impactos y actor protagónico. Comuna 13 de Medellín (Colombia)

\begin{tabular}{|c|c|c|c|}
\hline $\begin{array}{l}\text { Repertorios } \\
\text { de acción } \\
\text { identificados }\end{array}$ & Estrategias desplegadas & Impacto 6 consecuencia & Actor político \\
\hline $\begin{array}{l}\text { Reclamación y } \\
\text { denuncia }\end{array}$ & $\begin{array}{l}\text { Marchas, videos testimoniales, } \\
\text { plantón en instituciones. }\end{array}$ & $\begin{array}{c}\text { Contrarrestar la violencia y } \\
\text { defender la vida. }\end{array}$ & $\begin{array}{c}\text { La Elite Hip Hop, } \\
\text { Son Batá } \\
\text { Asociación Mujeres de Las } \\
\text { Independencias (AMI). }\end{array}$ \\
\hline Resistencia civil & $\begin{array}{c}\text { Recorridos artísticos, } \\
\text { conciertos anuales, Escucha } \\
\text { Comunitaria, creación de redes } \\
\text { sociales y articulación del } \\
\text { trabajo comunitario. }\end{array}$ & $\begin{array}{c}\text { Resistir la violencia y el control } \\
\text { armado. }\end{array}$ & $\begin{array}{c}\text { La Elite Hip Hop, } \\
\text { Son Batá } \\
\text { Corporación Juvenil Sal y Luz } \\
\text { Asociación Mujeres de Las } \\
\text { Independencias (AMI), }\end{array}$ \\
\hline $\begin{array}{c}\text { Construcción de } \\
\text { paz }\end{array}$ & $\begin{array}{l}\text { Bazares comunitarios, juegos } \\
\text { cooperativos de no-violencia, } \\
\text { recuperación de memoria } \\
\text { cultural, Fiesta por la Vida, } \\
\text { campeonato deportivo de } \\
\text { valores, planeación de } \\
\text { desarrollo local. }\end{array}$ & $\begin{array}{c}\text { Transformar las situaciones de } \\
\text { violencia } \\
\text { Y generar proyectos alternativos } \\
\text { de desarrollo local. }\end{array}$ & $\begin{array}{c}\text { Corpades, } \\
\text { Corporación Concejo } \\
\text { Comunitario Realizadores de } \\
\text { Sueños, } \\
\text { Asociación Cristiana de } \\
\text { Jóvenes. } \\
\text { Corporación Juvenil Sal y Luz } \\
\text { Red Cultural Expresarte, } \\
\text { Caravana por la Vida, } \\
\text { Jugandhi }\end{array}$ \\
\hline
\end{tabular}


ZULUAGA, M. L. A. Acciones colectivas frente a la violencia. Disquisiciones a partir...

Los repertorios de acción ${ }^{5}$ identificados en la Comuna 13 fueron, en primer lugar, los de reclamación y denuncia; con el despliegue de estrategias como las marchas, las protestas simbólicas con la agitación de pañuelos y sábanas blancas en calles y terrazas ${ }^{6}$, los plantones en instituciones públicas y la producción de video documentales testimoniales de la situación de violencia y vulneración de los derechos fundamentales, donde se escenifica de forma irónica y crítica la situación de violencia y estigmatización experimentada por los pobladores de la Comuna 13. Además de la Marcha de la Solidaridad por la Vida y la Caravana por la Vida7, acciones colectivas a través de las cuales se buscó contrarrestar la violencia, denunciar la situación de guerra, confrontar a los actores armados, crear solidaridad externa y defender la vida frente a los violentos.

“En la Marcha de Solidaridad por la Vida desfilamos por todos los morros, habíamos más de 2000 mujeres. La iniciativa fue de las mujeres por que no queríamos tanta violencia, se hicieron murales muy bonitos. La intención era decir que las mujeres estábamos presentes y nos solidarizábamos con lo que había pasado. Las mujeres presentes nos solidarizamos con la 13, con tantos atropellos, violación a los derechos humanos" ${ }^{8}$ (Líder 1, 2007).

En segundo lugar, la identificación de repertorios de resistencia civil, con el uso de distintas estrategias tales como los recorridos artísticos y musicales por territorios vedados por los grupos armados para la libre circulación de los pobladores, los conciertos anuales de Revolución Sin Muertos, las actividades de Escucha Comunitaria ${ }^{9}$, la alborada anual de la chirimía, la creación de redes sociales y articulación del trabajo comunitario, las caminatas nocturnas por los diferentes barrios de la Comuna 13, acciones a través de las cuales se ha buscado resistir la violencia y el control armado de una manera pacífica y disimulada, aunque incisiva y constante.

\begin{abstract}
“En el año 2002 se realizó el primer concierto Operación Elite Hip Hop Centro Occidental, con la consigna 'En la 13 la violencia no nos vence'. Dos años conservó el nombre y luego pasó a llamarse Revolución Sin Muertos y este año va para la cuarta versión (2007).

Después de la Mariscal (operativo militar) se logró realizar el primer festival grande en contra de la estigmatización. 'En la 13 la violencia no nos vence', cogieron el lenguaje militar y como fue el Comando Elite los que hicieron la intervención militar era también una
\end{abstract}

\footnotetext{
${ }^{5}$ Siguiendo a Tarrow, "El repertorio es, a la vez, un concepto estructural y un concepto cultural, que incluye no sólo lo que los contendientes hacen, cuando están inmersos en un conflicto contra otros, sino lo que saben hacery lo que los otros esperan que hagan. Si en la Francia del siglos XVIII los descontentos hubieran recurrido a las sentadas, sus oponentes no habrían sabido cómo responder a ellas, del mismo modo que no lo sabría la víctima de un charivari en el campus de una universidad de nuestros días. Como escribe Arthur Stinchcombe, "Los elementos del repertorio son (...) a la vez las habilidades de los miembros de la población y las formas culturales de la población (1987)" (TARRow, 2004, p. 59)

${ }^{6}$ La Protesta de Las Sábanas Blancas, acción colectiva a la que toda la comunidad se unió extendiendo Sábanas y telas blancas en sus ventanas y tejados como forma de protestar y defender sus vidas, en respuesta al despliegue y ataque de la fuerza pública por aire y tierra sobre los techos y calles de la Comuna 13 de Medellín, que se llevó a cabo en el año 2002.

7 Consistió en un recorrido festivo y colorido de malabares, comparsas, música, baile y disfraces, llevado a cabo por los barrios conocidos como epicentro del conflicto armado durante el año 2002. Al final de este recorrido artístico y musical se realizó un Plantón Musical en un espacio céntrico y aglutinador de estos barrios (el atrio de la iglesia 20 de Julio), con la lectura pública de consignas y reflexiones en contra de la guerra.

8 Entrevista a líder de AMI, noviembre de 2007.

${ }^{9}$ Espacio para que las mujeres de estos barrios puedan expresar sus tristezas y angustias generadas por la violencia y amenaza contra la vida de sus seres queridos en la sede de AMI. Actividad programada una vez a la semana.
} 
OPINIÃO PÚBLICA, Campinas, vol. 18, no 2, novembro, 2012, p. 427 - 451

forma de protesta llamarse como grupo musical La Elite. Cantaron 26 grupos, se reconocieron entre ellos y en la comuna. Simbólicamente estuvo muy lleno de discursos. Mensajes: resistencia civil activa desde una postura de la no-violencia. Fue un concierto en medio del conflicto en septiembre, al final del concierto se escuchaban explosiones de granadas en los barrios de arriba ${ }^{10 "}$ (Líder 1, 2007).

Y en tercer lugar, se identificó el repertorio de acciones en construcción de la paz y democratización de la vida local, con la realización de bazares comunitarios consistentes en el intercambio solidario de productos, los juegos cooperativos de no-violencia con niños y niñas en plazas y sitios de encuentro público con una filosofía de la no-violencia, la realización de talleres artísticos y literarios, la recuperación de la memoria cultural, el ahorro colectivo, la construcción de espacios colectivos auto-sostenibles, las fiestas por la vida, los campeonatos deportivos en valores y los proyectos de planeación y desarrollo local.

Otras de éstas estrategias de acción son la proyección de películas al aire libre, la producción de medios comunitarios de comunicación escrita y audiovisual, convocadas entre otras por las organizaciones sociales de la Comuna 13, buscando, de este modo, la vinculación, la participación y el reconocimiento de los jóvenes y pobladores en general, para habitar las calles, plazas públicas y sitios identificados localmente como territorios de guerra y confrontación armada entre los bandos enfrentados. Habitando así, los espacios de la guerra con acciones que expresan vida y libertad, todas estas son estrategias de acción que han buscado transformar las situaciones de violencia y configurar una visión alternativa a la guerra.

A continuación se describen sintéticamente las características de las experiencias de acción colectiva identificadas:

- Los distintos repertorios de acción que se han producido colectivamente, han enfrentado directa e indirectamente el control y amenaza de los actores armados en el territorio, a través de la existencia de un trabajo en red donde cada acción colectiva ha sido convocada por una organización comunitaria, y ésta, a su vez, ha sido seguida, acompañada y fortalecida por los demás actores sociales de la Comuna 13. También recibiendo el apoyo de organizaciones no gubernamentales del orden nacional e internacional, restándole capacidad de poder social a los grupos armados sobre un territorio que han mantenido en estado de zozobra permanente.

- En general para los distintos colectivos mencionados, lo característica del proceso de creación de la acción colectiva ha sido la vehemente convicción de enfrentar la violencia, generando para ello las diferentes estrategias, gestiones e iniciativas por parte de cada uno de los sujetos colectivos. Algunas de éstas iniciativas tienen un carácter pacífico y no-violento, otras son críticas, confrontadoras y resistentes frente al actor armado, y, otras más, son constitutivas de opciones políticas ciudadanas de autonomía y democratización social.

\footnotetext{
${ }^{10}$ Entrevista a líder facilitar del proceso de organización de las agrupaciones de hip hop en la Comuna 13. Medellín, noviembre de 2007.
} 
ZULUAGA, M. L. A. Acciones colectivas frente a la violencia. Disquisiciones a partir...

- Sin embargo, existen quiebres al momento de generar las propuestas políticas alternativas y de reproducir la información y el auto-reconocimiento de cada actor colectivo, debido a que los temas y propuestas se siguen gestionando a modo particular de cada organización social y con un carácter muy localizado en el barrio o sector de procedencia. Ésta es una situación propia de las dinámicas heterogéneas que políticamente se ciernen en la vida cotidiana, lo que produce una fragmentación de la movilización social frente a la violencia y el conflicto armado en la Comuna 13, dificultando, a su vez, la continuidad y el reconocimiento externo de procesos sociales y políticos más amplios tendiente a mejorar el impacto sobre la situación de violencia que se pretende transformar. Estos quiebres tienen un origen más interno a la movilización social general de la Comuna 13, debido la inexistencia de un plan aglutinador de creación y posicionamiento de un proyecto político y social común a todas las organizaciones sociales.

- Aún así, se ha dado la convergencia del trabajo organizativo de las organizaciones comunitarias articulado a la organización en red, donde todas las agrupaciones juveniles de la zona reunidas, por ejemplo, en la red Uniendo Sueños, o la Red Cultural Expresarte, además de fortalecer las relaciones entre las organizaciones de la Comuna 13, generan otros vínculos con otras instituciones de la ciudad. y, a partir de cada acción colectiva, se han visibilizado posibles aliados y ejercicios compartidos de conocimientos y recursos entre los distintos actores colectivos existentes para comenzar a mejorar la comunicación y el impacto de la movilización social ante el resto de la sociedad.

- Los conciertos musicales y las marchas de denuncia de la situación de violación de los derechos humanos han sido las actividades que han registrado el mensaje movilizador de manera más contundente y directa, visibilizando la situación de violencia y sometimiento armado en el que han vivido los pobladores, con mayor difusión y apoyo por parte de otros sujetos colectivos y organizaciones no gubernamentales. Activando, a su vez, la participación de los ciudadanos habitantes de otros barrios y otras zonas de la ciudad de Medellín y Colombia.

- Una de las dificultades internas más frecuentes para la construcción de cada una de las acciones colectivas identificadas en la Comuna 13 ha sido la consecución de recursos económicos para llevar a cabo distintas iniciativas, sostenerlas en el tiempo y tener mayor poder de convocatoria en todos los barrios de la comuna 13, e incluso en la ciudad de Medellín. Aunque algunas de las experiencias colectivas han incursionado en estrategias de autogestión efectivas, la expectativa casi exclusiva en la consecución de recursos públicos hace a algunas de estas iniciativas ubicarse en un limbo moral, al poner a los activistas en una situación de dependencia de las mismas políticas institucionales que muchas veces han generado el malestar social y político que ha motivado la acción colectiva frente a la violencia. Sin embargo, esta es una situación que los propios líderes deberán dilucidar, valga para el análisis reconocer que ningún proceso organizativo es totalmente autónomo o independiente, la gestión de recursos públicos para las acciones colectivas de contestación y generación de alternativas ciudadanas constituyen formas de crear, en palabras de Zibechi (2007), "mecanismos de 
OPINIÃO PÚBLICA, Campinas, vol. 18, n², novembro, 2012, p. 427 - 451

compensación de las desigualdades" y no como se considera desde una perspectiva esencialista de la organización social y política, formas de dependencia y acumulación.

- Relacionado con lo anterior, la convocatoria y activación de la movilización se ha dado desde un ámbito excesivamente localista, entre otros aspectos, por el acercamiento y utilización de canales de difusión dirigidos casi exclusivamente a un grupo poblacional de la comuna; la mayoría de las convocatorias se enfocan a jóvenes (con excepción de algunas experiencias que se han enfocado en los grupos de mujeres, niños y niñas de la comuna), sin mayores propósitos de extender el mensaje movilizador frente a la violencia a otras personas no sólo de la comuna, también de la ciudad, el país y al ámbito internacional -sin necesidad de mayores recursos, por ejemplo, a través de un medio como el Internet siguiendo otras campañas movilizadoras exitosas-, buscando de este modo, ampliar la vinculación y participación de toda la población en el proceso de la acción colectiva.

- Otra dificultad interna es la poca formación educativa de líderes e integrantes de las organizaciones sociales para el logro del fortalecimiento de los procesos colectivos internos y de la renovación de liderazgos, este aspecto tiene que ver, entre otros, con las mínimas oportunidades individuales para el desarrollo humano con las que se ha contado, al igual que los mínimos mecanismos institucionales existentes para potenciar la participación ciudadana en el desarrollo de proyectos educativos, económicos y sociales.

- Además de la amenaza directa sobre los colectivos sociales de la Comuna 13 proveniente del asesinato, amenaza y desplazamiento forzado de líderes y personas que conforman las organizaciones sociales, también representa una amenaza a los procesos de organización social y política la intimidación y suplantación de organizaciones sociales por parte de los actores armados interesados en controlar política y socialmente a la población civil, y con esto, la aparición de fronteras difusas entre el espacio utilizado por los actores colectivos; ya sea que estén enfrentando la violencia desde la oposición, la resistencia civil, o la construcción ciudadana de alternativas políticas y sociales, y los actores armados en su interés de cooptar y sustituir a los lideres políticos y sociales en el territorio controlado violentamente.

- Estos grupos armados han buscado legitimar su presencia ofreciendo prebendas, por ejemplo, el pago de transporte y entradas gratuitas para que los niños y niñas de los barrios visiten los parques de diversión de la ciudad. Además, los actores armados también han buscado cooptar a los líderes comunitarios para legitimar socialmente la presencia y control del territorio, haciendo que los líderes cívicos y comunitarios trabajen con ellos en la realización de las convocatorias de la población para actividades lúdicas, como es el caso de los Festivales de Cerveza o los paseos a parques de diversión de la ciudad. Los actores armados también se han tomado organizaciones que antes eran lideradas por líderes cívicos y comunitarios, lo que ha significado un "reacomodo" del liderazgo comunitario, ahora por cuenta y "representación" de los actores armados.

- Una oportunidad interna para la acción colectiva ha sido la inauguración y recreación de repertorios de acción adoptados de las actividades artísticas y prácticas culturales, que posibilitan de un modo lúdico y festivo, pero también cifrado y disperso, la difusión de 
ZULUAGA, M. L. A. Acciones colectivas frente a la violencia. Disquisiciones a partir...

mensajes que comunican y comparten representaciones ideológicas de oposición y contestación, así como la autonomía de sus acciones civilistas. Ha sido a través de dichas actividades artísticas y culturales que se han establecido relaciones de confianza, empatía y solidaridad entre los integrantes de los colectivos, alterando de algún modo las relaciones de poder local existentes con la constitución de identidades colectivas.

- Otra oportunidad interna ha sido la identificación y el reconocimiento de las tácticas bélicas llevadas a cabo en el fragor del conflicto armado, debido a que con ese conocimiento se ha logrado sobrellevar la amenaza bélica permanente, aprendiendo de aquellas situaciones que pueden generar mayores riesgos para el colectivo y para la integridad física de cada persona integrante del proceso comunitario. Es en esa dinámica social colectiva, a partir de la percepción de cada integrante, que se ha logrado comprender la situación de confrontación armada en la que se han encontrado y, de este modo, identificar aliados y adversarios en el desarrollo de la acción colectiva civilista.

\section{Principales aportes al tema de la acción colectiva}

No todo en el proceso organizativo descrito son apuestas alternativas de oposición al dominio armado, la polarización de la población es una de las características de cualquier sociedad que ha experimentado un conflicto interno armado tan prolongado como el de la sociedad colombiana. Además, muchas otras acciones colectivas se producen orientadas por la inclusión y la participación en el modelo hegemónico de dominación política y cultural, frente a esta situación es pertinente la reflexión de Gledhill cuando hace la siguiente crítica:

\footnotetext{
“(...) los autores relacionados con los 'estudios subalternos' suponían que existía una especie de 'conciencia subalterna' pura y auténtica, a la que no afectaban los discursos ni las prácticas coloniales. Tal como han mostrado autores como Keesing, estos sujetos completamente 'autónomos' no existen, y la idea de que hay espacios de vida social subalterna que no se hallan en absoluto colonizados por las relaciones de poder constituye un funesto punto débil en las teorías de James Scott" (GLEDHILL, 2000, p. 115).
}

La acción colectiva en el contexto y resultados descritos, ha significado una "performance" de lo diverso. Una fuerza popular basada en diferentes racionalidades para resistir la violencia y la amenaza latente y directa de la vida colectiva e individual, constituyéndose en una representación tal que supera la lucha de la "sobrevivencia" y se arriesga a la lucha por nuevas posibilidades políticas; de autonomía relativa, de reconocimiento de derechos y responsabilidades individuales y colectivas, con la voluntad de alterar la realidad política conflictiva.

Sin embargo, los resultados de la acción colectiva son parciales, finalmente no se ha logrado eliminar los distintos ordenes de violencia frente a los cuales se han manifestado, pero éste es un proceso colectivo inacabado, es discontinuo y ambiguo en sus alcances. Se va configurando y recreando conforme van surgiendo conflictos y alteraciones de los significados compartidos colectivamente. Por ello, es pertinente la siguiente critica de Escobar, "no pocas veces se ha esencializado a la sociedad civil 
OPINIÃO PÚBLICA, Campinas, vol. 18, no 2, novembro, 2012, p. 427 - 451

en un marco positivo, como el terreno de lo bueno y lo luminado (...) olvidando que también forjan "un espacio social Ileno de ambigüedad, ironía y conflicto" (ESCOBAR, 1999, p. 163).

Aún así, cada experiencia colectiva ha tenido logros relacionados con su capacidad organizativa y de liderazgo social y político, entre estos, la formación política y social, el reconocimiento de potencialidades individuales y colectivas para afrontar los riesgos del trabajo comunitario y a los mismos actores armados, y la capacidad de verbalizar y comunicar lo que han vivido y sentido en situaciones extremas de precariedad económica y social, pero también, de indignación y de dolor físico y moral ante la violencia.

Algunos de los colectivos, lograron con las canciones, de manera metafórica y directa, narrar la situación que vivían con las letras que se pronuncian, ubicándose, a su vez, en una nueva posición social y política, en contra de la estigmatización y revindicando su posición civil fuera de la guerra.

\footnotetext{
"Así como arriba hacían bulla con las balas (en los barrios epicentro del conflicto) y esos eran sus instrumentos, nosotros queríamos hacer sonar lo de nosotros, jóvenes con otros instrumentos que estábamos trabajando por muchas cosas y el hip hop era el medio. Teníamos otras visiones de vida y buscábamos otras opciones, decir que no queríamos más guerra era lo que queríamos ${ }^{11 "}$ (Líder 3, 2007).
}

A otros colectivos les permitió la posibilidad de hablar y compartir proyectos comunes, estos fueron espacios de solidaridad y encuentro que les dio la fuerza para no vincularse a la guerra.

\begin{abstract}
“(...) La guerra era un arma de doble filo, pues traía unos problemas pero nos ayudaba con muchas cosas, nos daba la fuerza para seguir trabajando; no todos los de la comuna somos guerrilleros y poder demostrar que se estaba haciendo otras cosas y no todos tenemos un fusil y no somos como dijo el secretario de gobierno que decía que los de la 13 nos merecíamos lo que nos estaba pasando, por que éramos colaboradores de los grupos armados.

Durante todo el conflicto los jóvenes que han estado en los grupos artísticos y musicales no han hecho parte de la guerra, no han tocado un arma, nos han tocado durísimo (con el asesinato de familiares y amigos), pero no hemos caído porque tenemos el arte, eso nos ha permitido mantenernos firmes. Nuestro lema es 'Música para el alma', es la expresión que yo tengo para sentir y, desde ahí, crear ${ }^{12 “ " ~(L i ́ d e r ~ 4, ~ 2007) . ~}$
\end{abstract}

La constitución de las distintas experiencias de acción colectiva en torno al hip-hop, al juego cooperativo y no-violento, a la elaboración de artesanías y artículos producidos manualmente, al ahorro colectivo, así como al rescate del folclor, la memoria y la identidad afro-descendiente, se han producido desde las perspectivas juveniles, de género y una política cultural en torno a la integración barrial. Las capacitaciones y proyecciones del desarrollo local son experiencias colectivas que han significado

\footnotetext{
11 Entrevista a Joven integrante de la agrupación Elite Hip Hop, noviembre de 2007.

12 Entrevista a líder de la agrupación Son Bata. Diciembre de 2007.
} 
ZULUAGA, M. L. A. Acciones colectivas frente a la violencia. Disquisiciones a partir...

diversos espacios de solidaridad y promoción de la música, la danza, la creación, pero también de la alteración de las relaciones de poder en la población.

Esta alteración en las relaciones de poder se ha dado a lo largo de los últimos años de forma lenta, aunque también con reveses, pero significativa para cada uno de los colectivos sociales analizados, a través de propuestas concretas como la de vencer el estigma que dejó las operaciones militares en la población de la Comuna 13, la creación de un espacio alternativo de jóvenes, niños y niñas para alejarse de propuestas de vida alrededor de las armas. La construcción de ofertas artísticas y musicales auto. sostenibles, la muestra y divulgación del trabajo de las organizaciones comunitarias de la comuna y la búsqueda e interlocución con otras organizaciones para la gestión del desarrollo zonal, a través del liderazgo y procesos de organización y participación para un desarrollo social que busca integrar a toda la población de la Comuna 13.

Todo el proceso de las experiencias presentadas ha sido una creación colectiva persistente, y dialogar con otros actores de la ciudad les ayudó a cualificar su discurso de identidad frente a la violencia, a fortalecerse internamente y a generar nuevos aprendizajes frente a la planeación y la gestión de proyectos. De este modo, las distintas expresiones culturales se han convertido en opción de vida que articula la acción colectiva frente al conflicto y posiciona a los jóvenes y mujeres, en particular, como interlocutores directos de organizaciones sociales, ya no como víctimas o personas reclutadas para engrosar las filas de algún actor armado, sino como los artífices de sus propios destinos.

\footnotetext{
“Después del conflicto, la comuna dio un cambio muy importante de participación, nace como la necesidad de articulación, de espacios en donde se reúnan fuerzas y empezar a planear, ahí se empieza a pensar en el plan de desarrollo de la 13. Se empezó con reuniones de organizaciones; Corapaz, Realizadores y Sal y Luz lideraron el proceso. En el 2003 se sientan las tres organizaciones y se piensan el proceso de articulación comunitaria y en el 2004 se inicia el proyecto del Plan de Desarrollo.

El conflicto ha seguido, no se han solucionado los problemas y la guerra sigue pero de todas maneras ese periodo permitió reaccionar y gestar cambios.

El mismo trabajo que hacen las organizaciones en (Comuna) la 13 hacen parte de esa resistencia, aunque no es directa al conflicto estamos haciendo una acción para hacerle ver a la ciudad que la comuna 13 no es como la están pintando13" (Líder 5, 2007).
}

Lo que permite afirmar, a partir de los casos analizados, la existencia de una suerte de voluntades dispersas (VIRNO, 2003; 2004) para la generación de nuevas narrativas comunitarias de autonomía colectiva y nuevos proyectos de desarrollo comunitario que involucra la diversidad de fuerzas sociales y la solidaridad efectiva. Los jóvenes con intencionalidad política disidente frente a los actores armados y a las violaciones a los derechos humanos, se han dado cuenta que tienen mucho que aportar a la construcción de comuna y de ciudad, lo que ha propiciado la articulación de actores sociales juveniles en torno a la planeación de un futuro por fuera del conflicto armado, a la vez que la creación de

\footnotetext{
${ }^{13}$ Entrevista a integrante de la Corporación Sal y Luz, Diciembre de 2007.
} 
OPINIÃO PÚBLICA, Campinas, vol. 18, no 2, novembro, 2012, p. 427 - 451

liderazgos femeninos y de confirmación de la autonomía ciudadana, con la generación de mecanismos de reflexión frente a las vivencias y la cotidianidad con los actores armados.

Uno de los aportes a la interpretación de la acción colectiva es que el impacto alcanzado de experiencias colectivas tan vitales en unas condiciones tan específicas, políticas, económicas y sociales de guerra y exclusión, es que a pesar del aparente hermetismo del poder armado, esas acciones colectivas con sus pisadas silenciosas logran en forma de susurro poner en evidencia lo impenetrable, el poder de los ejércitos intimidante y proscrito no puede controlarlo todo, existen rendijas, por las que menudos rayos de luz pueden convertirse en potentes bolas de fuego. Ese poder circulando la totalidad del cuerpo social del que hablaba Foucault está aquí construyendo uno de esos devenires, y representándose a sí mismo. Las organizaciones sociales han aprendido, por ejemplo, a moverse con cautela en territorios en conflicto armado y en la dinámica de los grupos ilegales y legales, por el control, ya no solo militar, sino también social y político.

Otro aporte a la interpretación de las acciones colectivas es su identificación como una expresión política, que está enviando mensajes sobre la posibilidad de construir un proyecto común de sociedad no autoritario ni excluyente, refundando la política no sólo en el ámbito local, a través de un proceso de participación social que recoge contenidos de los cambios y desafíos que tiene la política en el ámbito global como vía hacia la democratización y promoción de derechos ciudadanos. El poder de los llamados débiles o subyugados, se convierte en esta perspectiva, en un ejercicio constructivo, imaginativo y creativo, en una interacción de fuerzas. Es una de las múltiples posibilidades existentes de poner a circular el poder. Frente al poder de facto, frente al poder ejercido por medios violentos, siempre habrá posibilidades de deslizarse y escabullirse, otras tecnologías y otros repertorios de acción serán inaugurados, renovados, reencauchados, como otras más, de las tácticas de ingenio y posibilidad de los llamados "débiles".

De acuerdo con Virno, mientras la multitud postfordista continué teniendo puesta la camiseta del Pueblo, hasta que no invente formas políticas que estén a la altura de su manera de ser (de producir, de comunicar, de habitar el mundo), continuarán multiplicándose experimentos políticos autoritarios" (VIRNO, 2004, p. 21). La política cultural que se viene construyendo en la Comuna 13 a través de los distintos procesos de acción colectiva frente a la violencia, es una producción de espacios para la discusión, a la par que la construcción, de lo común compartido, de una forma genuina y valiosa de enfrentar los proyectos políticos y militares autoritarios en sus territorios de vida.

La heterogeneidad es la característica en las estrategias desplegadas por los actores sociales, políticos y culturales en cuanto a qué hacer en respuesta a la situación de violencia, cada colectivo tiene sus propias perspectivas de acción, aunque el objetivo sea el mismo: afrontar la violencia. Por ejemplo, en esa democratización de los lugares públicos, una de las estrategias ha sido la de eliminar las fronteras bélicas imaginarias, que impiden la circulación entre sectores de los barrios a todos los moradores, atreviéndose a pasar de un barrio a otro con la excusa de la creación de una comparsa o manifestación artística, detrás de la cual, se han logrado derrumbar la prohibición del cruce por fronteras impuestas por los bandos armados, lo que significa para todos y todas nuevos horizontes de posibilidad distintos al conflicto armado. Siguiendo este planteamiento, Escobar afirma, 
ZULUAGA, M. L. A. Acciones colectivas frente a la violencia. Disquisiciones a partir...

“(...) quizá, la política cultural es más evidente cuando los movimientos hacen reclamos basados en aspectos culturales (...) o en aquellos que utilizan la cultura como un medio para captar o movilizar activistas (...) No obstante queremos subrayar que la política cultural también es ejecutada cuando los movimientos intervienen en debates alrededor de políticas, intentan resignificar las interpretaciones dominantes de lo político o desafían prácticas políticas establecidas" (EscoBAR, 1999, p. 142).

La actitud vehemente de los distintos actores colectivos frente al poder ejercido por los grupos armados, ha sido una postura política de creencia en la "eficacia de la acción colectiva". Esta creencia ha consistido en la posibilidad de alterar las relaciones de poder existentes y en el impacto positivo que pueda tener el mensaje civil alternativo, a través de las distintas estrategias y repertorios desplegados frente al control y dominación de los grupos armados sobre las vidas de los pobladores. Ninguna de las acciones colectivas se hubiese podido llevar a cabo sin la confluencia de las motivaciones y orientaciones de acción de los integrantes y activistas, que han llegado a compartir valores, intereses y definiciones de la realidad, Ilegando a identificarse y solidarizarse activamente, frente al ejercicio arbitrario y autoritario del poder armado en sus territorios.

\section{Conclusiones}

Las preguntas que orientaron el estudio de casos fueron abordadas desde una lectura abierta a las narraciones de los líderes y actores colectivos entrevistados, el sesgo analítico consistió en ceñirse a aquellas acciones colectivas que buscaban enfrentar las situaciones de violencia generadas por el conflicto armado que vivían sus protagonistas. Pero, más allá de esto, fue un proceso interno de construir un estudio dignificante de los pobladores, que visualizara, a su vez, lo genuino del encuentro del investigador con el proceso organizativo, y también del encuentro mismo entre las distintas organizaciones sociales y sus propias vivencias. Es por esto que se buscó, y, en gran parte se logró, desprenderse de cualquier idea preconcebida de la lógica y orientación política que movía a los distintos pobladores a actuar frente a la violencia, como pudiese ser hablar de la acción colectiva exclusivamente desde la resistencia civil, desde la oposición o desde cualquier otra lógica de acción en particular.

Aunque los logros de cada una de las acciones colectivas en la Comuna 13 son más singulares, localizados y ambiguos de lo que se quisiera, tienen la fuerza significativa de haberse pronunciado, de surgir volviendo porosas unas relaciones de dominación aparentemente impenetrables. Aunque la movilización social producida en la Comuna 13 no ha logrado transformar la situación de violencia, ha generado procesos de apertura de otros mensajes y estrategias de acción diferentes al accionar bélico. Esto es, mensajes que sirven de ejercicio de apertura de oportunidad política para el reconocimiento y defensa de los derechos civiles y políticos que no han sido hasta ahora garantizados parcial, ni mucho menos plenamente, en estas comunidades.

A pesar de las limitaciones internas y externas existentes, de acuerdo a las especificidades locales descritas, la heterogeneidad de actores sociales, políticos y culturales ha logrado, de un lado, reconocer sus posibilidades y potencialidades de acción, y de otro lado, invertir muchas de las amenazas reales como oportunidades políticas, cada uno actuando desde sus propias perspectivas y condiciones 
OPINIÃO PÚBLICA, Campinas, vol. 18, no 2, novembro, 2012, p. 427 - 451

de posibilidad. Dando cuenta en dichas perspectivas, de la diversidad de las acciones colectivas que se han producido para enfrentar la violencia en la Comuna 13 de Medellín. Pero más allá de esto, de la existencia de las distintas formas de manifestarse frente a la violencia, llegando a significar un conflicto simbólico, de acuerdo con Melucci, que plantea alteraciones de las relaciones hegemónicas de dominación, aunque en sí mismas no socaven las estructuras del poder, y tampoco sea ésa la motivación que movilice a la acción colectiva.

Sin embargo, en contextos de conflictividad violenta como lo demuestra el estudio de casos de la Comuna 13 de Medellín, no necesariamente desaparecen o se desarticulan las acciones colectivas que preexistían al momento de violencia, todo lo contrario, es a partir de la nueva situación de amenaza y restricción, en el marco de la violencia, que distintos colectivos sociales, políticos y culturales utilizan y renuevan los repertorios de acción; inventándolos, reconfigurándolos y recreándolos para afrontar la violencia, llegando a posicionarse como grupos colectivos que han aumentado su poder frente al poder estatal y de los micro-poderes alternos bélicos de todo orden, al lograr construir alternativas políticas, sociales y culturales en sus espacios de acción.

Así, y como otra de las conclusiones de este estudio es, que pese a la represión sistemática de que han sido objeto las distintas manifestaciones y acciones colectivas en Colombia, y aún más, pese al despliegue discursivo de una sociedad cohesionada frente a la clase política y económica hegemónica, se evidencian distintas formas de acción colectiva que plantean la existencia de orientaciones y formas de acción opositoras a la dominación armada, e ilustradoras de una pluralidad de alternativas culturales, políticas y sociales, alterando, a su vez, las relaciones de subalternidad.

Cada uno de los colectivos mencionados en la Comuna 13 de Medellín, ha tenido la necesidad de superar muchas situaciones organizativas internas, además de las externas, para ampliar la participación a otros grupos sociales de la Comuna 13, lo que recuerda de nuevo a Tilly cuando plantea, "En general los organizadores deben trabajar arduamente para estimular la conciencia compartida de la opresión y la resolución de resistir, y que aún con intensos esfuerzos de organización fracasan excepto en circunstancias estructurales especiales" (TILLY, 2000, p. 234). Los mensajes que los activistas han producido para activar la participación de los habitantes de la Comuna 13 en cada una de las acciones colectivas, han ido incorporando la urgencia de creación de nuevos valores sociales, alrededor de la convivencia, el respeto a la vida y a las diferencias sociales, culturales y políticas de sus habitantes, frente a los valores dominantes como la competencia y el aniquilamiento del contrincante. En este sentido, los mensajes movilizadores de la acción colectiva en la Comuna 13 no siempre son directos o confrontadores de los grupos armados que ejercen control territorial. La contundencia de las voces que disienten de esa violencia debe evaluarse desde su carácter autónomo, pero incisivo frente a los proyectos de dominación excluyente y totalitaria, creando, a su vez, nuevas prácticas de relacionamiento culturales y políticas. 
ZULUAGA, M. L. A. Acciones colectivas frente a la violencia. Disquisiciones a partir...

\section{Referencias Bibliográficas}

Agamben, G. Estado de excepción. Homo Sacer II. Buenos Aires: Adriana Hidalgo Editora, 2005.

Appadural, A. "Soberanía sin territorialidad. Notas para una geografía posnacional”, Nueva Sociedad, n 163 , Buenos Aires, p. 109.124, 1999.

Bauman, Z. La globalización. Consecuencias humanas, México D. F.: Fondo de Cultura Económica, 1999.

“Los residuos del progreso económico”, Claves de Razón Práctica, n 149, Madrid, p. 14·20, 2005.

CASTELls, M. La ciudad informacional. Tecnologías de la información, reestructuración económica y el proceso urbano. regional. Madrid: Alianza Editorial, 1995.

DAS, V. Los significados de la seguridad en el contexto de la vida cotidiana. En: ORTEGA, F. A. (ed.). Veena Das: sujetos del dolor, agentes de dignidad. Bogotá, Universidad Nacional de Colombia, Facultad de Ciencias Humanas. CES, Universidad Nacional de Colombia sede Medellín, Pontificia Universidad Javeriana, Instituto Pensar, 2008.

Escobar, A. El final del salvaje. Naturaleza, cultura y política en la antropología contemporánea, Santafé de Bogotá: Instituto Colombiano de Antropología e Historia ICANH/CEREC, 1999.

Más allá del tercer mundo. Globalización y diferencia. Bogotá: Instituto Colombiano de Antropología e Historia ICANH / Universidad del Cauca, 2005.

Escobedo David, R. Magdalena Medio y departamento del Cesar: 1980-1998, p. 37-58. En: AldanA, W. et al. Conflictos regionales. Atlántico y Pacífico. Santafe de Bogotá: FESCOL-IEPRI, 1998.

FAJARDO, D. "Colombia: reforma agraria en la situación de conflictos armados". América Latina Hoy, n’ 23, Madrid, p.45. 59, 1999.

FAZIo VengOA, H. "De la globalización a la historia global: hacia otra representación del mundo contemporáneo", Análisis Político, n. 61, Bogotá, p. 28.44, 2007.

Foucault, M. Defender la sociedad. Curso en el Collage de France (1975-1976). Buenos Aires: Fondo de Cultura Económica, 2000.

Giddens, A. Consecuencias de la modernidad. Madrid: Alianza Universidad, 1993.

GLEDHILL, J. El poder y sus disfarces. Perspectivas antropológicas de la política. Barcelona: Ediciones Bellaterra, 2000.

GUERRERO, B. J. La sobre-politización del narcotráfico en Colombia en los años ochenta y sus interferencias en los procesos de paz. En: Peñaranda, R. y Guerrero, J. (eds.). De las armas a la política. Santafé de Bogotá: Tercer Mundo Editores, IEPRI, Universidad Nacional de Colombia, 1999.

Ignatieff, M. “Democracia y terrorismo", Claves de Razón Práctica, n 150, Madrid, p. 4-13, 2005.

Kaldor, M. "Cinco acepciones de la sociedad civil global”. Claves de Razón Práctica, n 149, Madrid, p. 30-35, 2005.

KaLYVAS, S. "La ontología de la 'violencia política': acción e identidad en las guerras civiles". Análisis Político, n 52 , Bogotá, p. 51·76, 2004.

Leal Buitrago, F. "10 años del Instituto de Estudios Políticos y Relaciones Internacionales". Análisis Político, n³0, Bogotá, p. 53-57, 1997.

LemkE, T. et al. Marx y Foucault. Buenos Aires: Nueva Visión. 2006.

MARCHAL, R.; MESSIANT, C. "Las guerras civiles en la era de la globalización: nuevos conflictos y nuevos paradigmas", Análisis Político, n’. 50, Bogotá, p.20-34, 2004.

Mattelart, A. Historia de la sociedad de la información. Barcelona: Paidós, 2002.

MelucCl, A. Challenging codes. Collective action in information age, Cambridge: Cambridge University Press, 1996. Acción colectiva, vida cotidiana y democracia. México D. F.: El Colegio de México, 1999.

MünkLeR, H. “Las guerras del siglo XXI”, Análisis Político, n51, Bogotá, p.3·11, 2004. 
OPINIÃO PÚBLICA, Campinas, vol. 18, no 2, novembro, 2012, p. 427 - 451

Viejas y nuevas guerras. Asimetría y privatización de la violencia, Madrid: Siglo XXI Editores, 2005.

Pecaut, D. “Presente, pasado y futuro de la violencia”. Análisis Político, n 30, Bogotá, p. 3·36, 1997.

PNUD. El conflicto, callejón con salida. Informe nacional de desarrollo humano. Bogotá, Colombia: PNUD, 2003.

SASSEN, S. "Una sociología de la globalización”. Análisis Político, n’ 61, Bogotá, p. 3·27, 2007.

ScotT, J. e. Los dominados y el arte de la resistencia. Discursos ocultos. México D. F.: Ediciones Era, 2000.

SubIRATS, E. "Violencia y civilización", El Viejo Topo, n 165, Barcelona, p. 45-55, 2002.

TARROW, S. El poder en movimiento. Los movimientos sociales, la acción colectiva y la política. Madrid: Alianza Editorial, 2004.

TILLY, C. La desigualdad persistente. Buenos Aires: Manantial, 2000.

Social movements 1768-2004. Boulder Co, Paradigm Publishers, 2004.

VIRNO, P. Virtuosismo y revolución: la acción política en la era del desencanto. Madrid: Traficantes de Sueños, 2003.

Ediciones, 2004

Cuando el verbo se hace carne. Lenguaje y naturaleza humana. Buenos Aires: Cactus/ Tinta Limón

Waldmann, P.; Reinares, F. Sociedades en guerra civil. Conflictos violentos de Europa y América Latina. Barcelona:

Paidós, 1999.

Zafford, F.; Palacios, M. Colombia: Fragmented land, divided society. New YorkOxford: Oxford University Press, 2002.

ZIBECHI, R. Dispersar el poder. Los movimientos sociales como poderes antiestatales. Bogotá: Ediciones Desde Abajo, 2007.

\section{Entrevistas:}

- Líder 1 [Entrevista Líder Asociación de Mujeres Las Independencias], 2007 por Mary Luz Alzate Zuluaga [trabajo de campo "Resistencia Civil No Armada al Conflicto Armado, la Exclusión Social y la Pobreza. Casos Comunas 8,9 y 13 de Medellín. 2002-2006" por Jaime Rafael Nieto López (investigador principal), Mary Luz Alzate y Katherine Higuita (co. investigadoras)], Medellín, Colombia.

- Líder 2 [Entrevista Líder Hip Hop], 2007 por Mary Luz Alzate Zuluaga [trabajo de campo "Resistencia Civil No Armada al Conflicto Armado, la Exclusión Social y la Pobreza. Casos Comunas 8, 9 y 13 de Medellín. 2002.2006" por Jaime Rafael Nieto López (investigador principal), Mary Luz Alzate y Katherine Higuita (co-investigadoras)], Medellín, Colombia.

- Líder 3 [Entrevista Líder Hip Hop], 2007 por Mary Luz Alzate Zuluaga [trabajo de campo "Resistencia Civil No Armada al Conflicto Armado, la Exclusión Social y la Pobreza. Casos Comunas 8, 9 y 13 de Medellín. 2002-2006" por Jaime Rafael Nieto López (investigador principal), Mary Luz Alzate y Katherine Higuita (co-investigadoras)], Medellín, Colombia.

- Líder 4 [Entrevista Líder Son Batá], 2007 por Mary Luz Alzate Zuluaga [trabajo de campo "Resistencia Civil No Armada al Conflicto Armado, la Exclusión Social y la Pobreza. Casos Comunas 8, 9 y 13 de Medellín. 2002-2006" por Jaime Rafael Nieto López (investigador principal), Mary Luz Alzate y Katherine Higuita (co-investigadoras)], Medellín, Colombia.

- Líder 5 [Entrevista Líder Agrupación Sal y Luz], 2007 por Mary Luz Alzate Zuluaga [trabajo de campo "Resistencia Civil No Armada al Conflicto Armado, la Exclusión Social y la Pobreza. Casos Comunas 8, 9 y 13 de Medellín. 2002. 
ZULUAGA, M. L. A. Acciones colectivas frente a la violencia. Disquisiciones a partir...

2006" por Jaime Rafael Nieto López (investigadora principal), Mary Luz Alzate y Katherine Higuita (co. investigadoras)], Medellín, Colombia.

Mary Luz Alzate Zuluaga·mary_alzate@yahoo.es

Submetido à publicação em março de 2011.

Versão final aprovada em março de 2012. 